\title{
ADSORÇÃO DE CÁDMIO EM SOLO DA CIDADE DE NEVES PAULISTA-SP
}

Lidia Maria de Almeida Plicas ${ }^{1}$

Débora Cristina Alves Cabral ${ }^{2}$

Flávio Fernando Manzini ${ }^{3}$

RESUMO: A contaminação do solo é um dos principais problemas ambientais, podendo ocorrer de diversas maneiras, sendo a principal causa fertilização e a calagem do solo, os quais, geralmente possuem em sua composição metais pesados. O objetivo deste estudo é avaliar a capacidade de adsorção de Cádmio em solo da cidade de Neves Paulista, com base nos modelos matemáticos de Langmuir e Freundlich, correlacionar a adsorção com os fatores $\mathrm{pH}$ e força iônica do meio e verificar, por meio da energia livre, a espontaneidade do processo de adsorção. Trata-se de solo arenoso de baixa acidez, pobre em matéria orgânica e com baixo teor de capacidade de troca iônica. Para avaliar a capacidade de adsorção de Cádmio, foram realizados experimentos variando a concentração do metal de 0 a $100 \mathrm{mg} \mathrm{L}^{-1}$. A adsorção foi avaliada em diferentes valores de $\mathrm{pH}$ e de força iônica do meio. Observou-se que o modelo de Langmuir se ajustou melhor à adsorção do metal. A adsorção ocorre de maneira favorável em meio de força iônica baixa, e tende a ser desfavorável em valores mais elevados, demonstrando assim uma correlação negativa. Em relação ao pH a correlação foi positiva à adsorção. Os

\footnotetext{
${ }^{1}$ Doutora em Físico-Química, Instituto de Biociências, Letras e Ciências Exatas, UNESP-SP plicas@ibilce.unesp.br

${ }^{2}$ Bacharel em Química Ambiental, Instituto de Biociências, Letras e Ciências Exatas, UNESP-SP deboracacabral@hotmail.com

${ }^{3}$ Doutor em Geologia Regional, Instituto de Biociências, Letras e Ciências Exatas, UNESP-SP fmanzini@ibilce.unesp.br
} 
valores da energia livre foram negativos, o que demonstra a espontaneidade dos processos de adsorção.

Palavras chave: Solo. Adsorção. Cádmio.

\section{INTRODUÇÃO}

A contaminação do solo é um dos principais problemas ambientais, pois por maio da lixiviação e percolação de algumas substâncias presentes e adicionados nele, pode ocorrer a contaminação das águas superficiais e subterrâneas, comprometendo sua qualidade, ou podendo também ser biodisponibilizado para as plantas, e através da cadeia alimentar serem transferidos para o homem.

Produtos agrícolas, como corretivos e fertilizantes, especificamente os fosforados, podem ter em sua composição metais pesados, representando assim, uma fonte de contaminação.

A avaliação da adsorção desses metais pode ser feita quantitativamente, por meio de isotermas, que analisa o equilíbrio da concentração na fase fluida e a concentração de espécies adsorvidas no adsorvente, o solo. A adsorção de metais ao solo permite verificar como estes se comportam, podendo prever a quantidade que será lixiviada e a que será biodisponibilizada às plantas. Assim, é possível determinar métodos de recuperação e prevenção de possíveis contaminações do solo por de metais pesados.

O objetivo desse trabalho foi determinar a adsorção de Cádmio, por espectrometria de absorção atômica, em solo da cidade de Neves Paulista, região de São José do Rio Preto, com base nas isotermas de adsorção de Langmuir e Freundlich, verificar a influência dos parâmetros $\mathrm{pH}$ e força iônica do meio na adsorção e verificar a espontaneidade do processo de adsorção.

\section{REVISÃO BIBLIOGRÁFICA}

\subsection{Solo}


O solo é um dos recursos naturais de relevante importância, pois garante as condições de sobrevivência na Terra, sobretudo porque a maior parte dos nossos alimentos, direta ou indiretamente, provém dos campos de cultivo e pastagens neles implantados. Além disso, sustentam campos, cerrados, florestas e recebem a águas das chuvas que depois emerge nas nascentes e mananciais (LEPSCH, 2002).

As rochas, ao serem expostas à atmosfera se tornam instáveis, iniciando os processos de modificações no aspecto físico e químico dos minerais presentes. Esse processo é chamado de intemperismo ou meteorização, podendo ser físico, químico ou biológico, e é responsável pela formação do material consolidado que dará inicio à formação do solo (LEPSCH, 2002). Estudos feitos em várias partes da Terra afirmam que a existência de diferentes tipos de solo é controlada por cinco fatores essenciais: clima, relevo, tempo, material de origem e a presença de organismos vivos.

A Pedologia que estuda o solo formado, levando em conta sua constituição, origem, morfologia, classificações e seus mapas, tendo como base o seu perfil. O perfil do solo são subdivisões verticais, chamadas de horizontes ou camadas sobrejacentes ao material de origem, que se formam a partir do processo de intemperismo (PRADO,1995).

Na região de São José do Rio Preto afloram as rochas sedimentares arenosas da formação São José do Rio Preto, unidade litoestratigmática de idade neocretáceo da Bacia Sedimentar Bauru. O solo é considerado Argissolo Vermelho-Amarelo, sendo constituído por material textural predominantemente arenoso no horizonte $\mathrm{A}$ e argissolo ou médio no horizonte $B$.

Naturalmente, os metais pesados estão presentes nos solos e em rochas, desde o seu processo de formação, porém, atualmente o solo tem se apresentado cada vez mais com maiores concentração desses metais, o qual é transferido para a cadeia alimentar dos animais e do homem. $\mathrm{O}$ aumento dos teores destes metais está associado à aplicação de corretivos e fertilizantes agrícolas, a produtos como lodo de esgoto, compostos de lixo urbano e resíduos de indústria ou mineração, e a utilização de água de irrigação contaminada (FERNANDES, 2007).

Os graus de mobilidade, atividade e biodisponibilidade desses metais no solo dependem de fatores, como $\mathrm{pH}$, temperatura, potencial redox, CTC, competição com outros metais, ligação com ânions e composição e força iônica da solução do solo 
(OLIVEIRA, 2004). No Brasil, a legislação ainda é falha ao tocante aos limites aceitáveis de metais pesados no solo.

\subsection{Processo de Adsorção}

Isotermas de adsorção são curvas obtidas a partir da quantidade de material adsorvido no adsorvente em função da concentração do material em equilíbrio na solução, a uma determinada temperatura constante. Equações matemáticas são propostas para demonstrar de maneira quantitativa a adsorção de solutos por sólidos. A técnica usada para gerar os dados de adsorção é simples, sendo uma quantidade conhecida do soluto adicionada ao sistema contendo uma quantidade conhecida de adsorvente. Considerando que a diferença entre a quantidade adicionada e a remanescente na solução encontra-se adsorvida na superfície adsorvente (BOHN et al., 2001). Algumas isotermas mais comuns estão apresentadas na Figura 1.

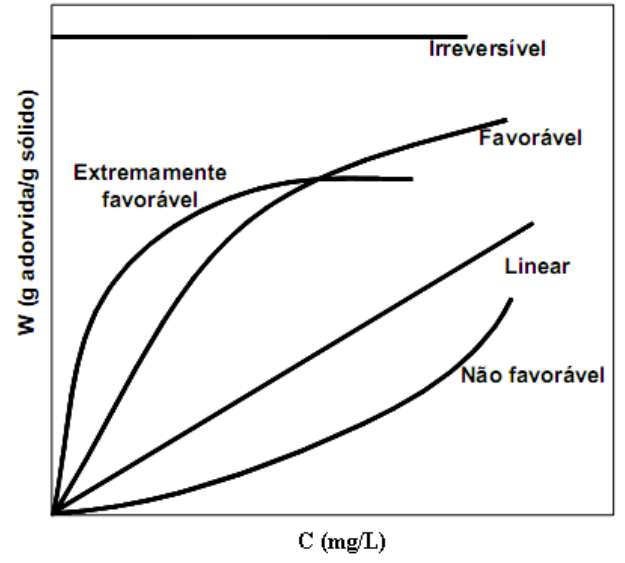

Figura 1. Tipos de isotermas de adsorção mais comuns

Fonte: Barros, 2004

Dois modelos são frequentemente utilizados para descrever a adsorção de íons nos solos, o modelo de Langmuir e o de Freundlich.

O modelo de Langmuir baseia-se em três hipóteses:

(a) a superfície de adsorção é homogênea, com isso, a adsorção é constante e independente da extensão da cobertura da superfície; 
(b) a adsorção ocorre em sítios específicos, sem interação com as moléculas do soluto;

(c) a adsorção torna-se máxima quando uma camada monomolecular cobre totalmente a superfície do adsorvente.

A adsorção baseada no modelo de Langmuir é apresentada na equação (1):

$$
\mathrm{Ce} / \text { Cads }=1 /\left(\mathrm{K}_{\mathrm{L}} \cdot \mathrm{Q}_{\mathrm{M}}\right)+\left(\mathrm{Ce} / \mathrm{Q}_{\mathrm{M}}\right)
$$

Em que Ce é a concentração do soluto na solução de equilíbrio $\left(\mathrm{mg} \mathrm{L}^{-1}\right)$, Cads é a quantidade de soluto adsorvido por massa de adsorvente $\left(\mathrm{mg} \mathrm{kg}^{-1}\right), \mathrm{K}_{\mathrm{L}}$ é a constante de afinidade relacionada à energia de ligação soluto-superfície adsorvente, e $\mathbf{Q}_{\mathbf{M}}$ é o limite superior de Cads, que mostra a capacidade máxima de adsorção do soluto ( $\left.\mathrm{mg} \mathrm{kg}^{-1}\right)$.

O modelo de Freundlich propõe que a energia de adsorção decresce logaritmicamente, à medida que a superfície vai se tornando coberta pelo soluto, o que a diferencia da equação de Langmuir. $O$ decréscimo na energia de adsorção com o aumento da superfície coberta pelo soluto é atribuído à heterogeneidade da superfície (BOHN et al., 2001).

A isoterma linearizada de Freundlich pode ser apresentada através da equação (2):

$$
\log \text { Cads }=\log \mathrm{K}_{\mathrm{f}}+(1 / \mathrm{n}) \log \mathrm{Ce}
$$

Onde Cads é a quantidade de soluto adsorvido por massa de adsorvente $\left(\mathrm{mg} \mathrm{kg}^{-1}\right)$, $\mathbf{K}_{\mathbf{f}}$ é o coeficiente de Freundlich, indica a capacidade do solo em reter o soluto ( $\mathrm{mg} \mathrm{g}^{-1}$ ), Ce é a concentração do soluto na solução de equilíbrio $\left(\mathrm{mg} \mathrm{L}^{-1}\right), \mathbf{n}$ indica a afinidade do solo pelo soluto, o qual é um parâmetro adimensional (SOARES, 2004).

\subsection{Fatores que influenciam a adsorção}

A literatura relata que $\mathrm{pH}$, potencial de oxi-redução, força iônica, textura, presença de cátions competindo pelos mesmos sítios de adsorção e os teores de matéria orgânica e de óxidos de $\mathrm{Fe}$ e Al são os principais fatores que influem na adsorção de Cádmio nos solos (PIERANGELI et al., 2005).

$\mathrm{O} \mathrm{pH}$ tem sido citado como um dos mais importantes fatores que influenciam na adsorção, por exercer influência na própria especiação do metal e em atributos relacionados com a sua adsorção, como o balanço de cargas na superfície dos colóides. 
Ma e Lindsay (1995) relatam que a atividade de $\mathrm{Cd}^{+2}$ em solução é altamente dependente do $\mathrm{pH}$.

A força iônica está diretamente relacionada com a composição da solução do solo, e influencia na atividade dos íons em solução e em outros atributos do solo, como o pH, a densidade de carga, a espessura da dupla camada elétrica difusa e o potencial eletrostático (SPOSITO, 1984). Se ocorrer a formação de complexos e a competição entre íons pelos sítios de adsorção, isso poderá interferir significativamente na atividade dos íons de $\mathrm{Cd}$ em solução e, portanto, seu potencial de lixiviação e biodisponibilidade (TEMMINGHOFF et al., 1995). A força iônica da solução do solo também pode variar, considerando a natureza do material de origem, o ambiente de intemperismo, os constituintes minerais e as práticas de manejo, como fertilização, calagem e adição de resíduos. Com isso, o efeito da força iônica sobre a adsorção é um fator importante a ser considerado nas análises de risco e do comportamento do Cádmio no ambiente (PIERANGELI, 2005).

\section{MATERIAIS E MÉTODOS}

\subsection{Materiais}

Utilizou-se vidrarias comuns de laboratórios, erlenmeyers de polipropileno, conjunto de filtração a vácuo, balança analítica OHAUS, balança semi-analítica GEHAKA, pHmetro (Digimed DM 22), mesa agitadora (Logen Scientific), centrífuga (Logen Scientific), membrana filtrante $0,45 \mu \mathrm{m}$ (Millipore) e espectrômetro de absorção atômica por chama (Varian, modelo SpectrAA 50B). Foram utilizados reagentes de grau P.A., e solução SpecSol, de $1000 \mathrm{mg} \mathrm{L}^{-1}$ de Cd, rastreada.

\subsection{Coleta e Preparo da Amostra}

As amostras de solo utilizadas no estudo realizado foram coletadas por Gonçalves (2009), na cidade de Neves Paulista, região de São José do Rio Preto, no Estado de São 
Paulo. Dividiu-se a propriedade em áreas uniformes de até 10 hectares, para a retirada de amostras, de um total de cinco glebas. Cada área foi percorrida em ziguezague, retirandose, com um trado, amostras de 15 a 20 pontos diferentes. Após a limpeza da superfície do solo, removendo detritos, as amostras foram retiradas da camada superficial, até a profundidade de $20 \mathrm{~cm}$, foram acondicionadas em sacos plásticos devidamente etiquetados. No laboratório formou-se uma amostra composta, utilizando alíquotas das cinco glebas. Em seguida, a amostra foi seca ao ar. A amostra foi homogeneizada, passando em peneira de $2 \mathrm{~mm}$ de abertura, resultando na Terra Fina Seca ao Ar (TFSA).

\subsection{Métodos para caracterização química e granulométrica do solo}

A caracterização do solo foi realizada por Macedo (2009), segundo Raij (2001), com as seguintes análises: $\mathrm{pH}$, em $\mathrm{H}_{2} \mathrm{O}$ e $\mathrm{CaCl}_{2}$, teor de matéria orgânica (M.O.), CTC e granulometria.

\subsection{Métodos para ensaios de adsorção de Cádmio em solo}

\subsubsection{Adsorção com variação da concentração do metal em pH natural do solo}

O procedimento foi realizado segundo o descrito por Lair et al. (2006). A quantidade de metal na solução foi determinada utilizando-se espectrômetro de absorção atômica por atomização por chama (EAA), em $\lambda=326,1 \mathrm{~nm}$, comprimento de onda específico para o metal. Trataram-se os dados empregando as isotermas linearizadas de Langmuir e Freundlich. $\mathrm{O}$ experimento foi realizado em duplicata.

\subsubsection{Adsorção com variação do pH do meio}

Pesaram-se alíquotas de $1,00 \mathrm{~g}$ de solo em erlenmeyers de polipropileno a estas adicionou-se $20 \mathrm{~mL}$ de solução de $\mathrm{CaCl}_{2} 0,01 \mathrm{~mol} \mathrm{~L}^{-1}$ e $10 \mathrm{~mL}$ da solução estoque do 
metal de $210 \mathrm{mg} \mathrm{L}^{-1}$. Ajustou-se o $\mathrm{pH}$, variando de 2 a 9, da matriz, com soluções de $\mathrm{HCl}$ e $\mathrm{NaOH}$ (ambas $0,1 \mathrm{~mol} \mathrm{~L}^{-1}$ ), tendo o cuidado de que o volume não ultrapassasse $2,5 \%$ do volume inicial da solução. O restante do procedimento foi o mesmo descrito por Lair et al. (2006). Quantificou-se o metal na solução filtrada utilizando EAA, em $\lambda=326,1 \mathrm{~nm}$. $O$ experimento foi realizado em duplicata.

\subsubsection{Adsorção com variação da concentração do metal e com a variação da força iônica do meio}

O procedimento foi realizado segundo o descrito por Lair et al. (2006). As forças iônicas (I) foram obtidas por meio de soluções aquosas de $\mathrm{CaCl}_{2}$ nas concentrações de $0,1 \mathrm{~mol} \mathrm{~L}^{-1}$ e $0,01 \mathrm{~mol} \mathrm{~L}^{-1}$ e de $\mathrm{NaCl} 0,01 \mathrm{~mol} \mathrm{~L}^{-1}, 0,1 \mathrm{~mol} \mathrm{~L}^{-1}$ e $1,0 \mathrm{~mol} \mathrm{~L}^{-1}$. A quantidade de metal na solução foi determinada por EAA, em $\lambda=326,1 \mathrm{~nm}$. Trataram-se os dados empregando as isotermas linearizadas de Langmuir e Freundlich. $O$ experimento foi realizado em duplicata.

\section{RESULTADOS E DISCUSSÃO}

\subsection{Análises química e granulométrica}

O solo usado foi analisado por Macedo (2009) e os resultados relevantes para o presente trabalho encontram-se dispostos na Tabela 1.

Tabela 1. Resultados da caracterização física e química do solo de Neves Paulista.

\begin{tabular}{|c|c|c|c|c|c|c|}
\hline \multicolumn{2}{|c|}{$\mathrm{pH}$} & \multicolumn{3}{|c|}{ Granulometria } & \multirow{2}{*}{$\frac{\text { M.O. }}{\text { g dm }}$} & \multirow{2}{*}{$\frac{\text { CTC }}{\mathrm{mmol}_{\mathrm{c}} \mathrm{dm}^{-3}}$} \\
\hline $\mathrm{H}_{2} \mathrm{O}$ & $\mathrm{CaCl}_{2}$ & Areia \% & Silte \% & Argila \% & & \\
\hline 5,93 & 5,63 & 78,0 & $\begin{array}{c}13,0 \\
\text { Fonte: Al }\end{array}$ & $\begin{array}{c}9,0 \\
\text { res, } 2012\end{array}$ & 7,19 & 74,61 \\
\hline
\end{tabular}

De acordo com Macedo (2009), o solo é considerado arenoso por apresentar quantidade de argila inferior a 15\%. Em geral, esse tipo de solo possui uma série de 
limitações quanto a prática do cultivo, apesar de render, em curto prazo, excelentes resultados na produção; em longo prazo, o solo necessitará de manejos especiais.

A taxa de matéria orgânica apresentada é considerada baixa, conforme Tomé Jr. (1997). O decréscimo da matéria orgânica no solo pode apresentar um aumento na densidade aparente do solo, dificultando a percolação da água, aumentando assim, o escoamento superficial e resultando em maiores taxas de erosão.

A porcentagem da capacidade de troca iônica é de grande importância para avaliação da fertilidade do solo, retenção de nutrientes e de água. A CTC varia com a quantidade de matéria orgânica no solo, sendo diretamente proporcionais (RAIJ apud GONÇALVES, 2009). A CTC foi calculada a partir da soma dos cátions $\mathrm{Na}^{+}, \mathrm{K}^{+}, \mathrm{Mg}^{+2}$, $\mathrm{Ca}^{+2}$ e acidez potencial $\left(\mathrm{H}^{+}+\mathrm{Al}^{+3}\right)$. Não existem parâmetros para classificação do valor da CTC, entretanto, pode ser considerada pequena tendo em vista o baixo teor de M.O.

Segundo Tomé Jr. (1997), a amostra de solo apresenta acidez baixa, em $\mathrm{CaCl}_{2}$, já em $\mathrm{H}_{2} \mathrm{O}$, a acidez é considerada média. $\mathrm{O} \mathrm{pH}$ em água normalmente, possui valores maiores entre 0,3 a 1,2 unidades em relação a valores de $\mathrm{pH}$ em $\mathrm{CaCl}_{2}$. A amostra de solo apresentou 0,3 unidades de variação, portando dentro do esperado.

\subsection{Determinação da capacidade de adsorção de Cádmio no solo}

\subsubsection{Isoterma de adsorção com variação da concentração do metal em pH natural do solo}

Para o estudo de adsorção do metal $\mathrm{Cd}$ no solo, determinou-se quantidade de metal adsorvido (Cads) no solo segundo a equação: Cads $=[(\mathrm{Ci}-\mathrm{Ce}) \times \mathrm{Vs}] / \mathrm{m}_{\mathrm{g}}$, onde Ci é a concentração inicial do metal na solução do solo $\left(\mathrm{mg} \mathrm{L}^{-1}\right)$, Vs é o volume total da solução de equilíbrio $(\mathrm{L})$ e $\mathrm{m}_{\mathrm{g}}(\mathrm{g})$ é a massa de solo para análise. Com os dados assim tratados, traçou-se o gráfico de Cads em função de Ce, obtendo-se a isoterma apresentada na Figura 2, este experimento foi realizado em meio de $\mathrm{pH}$ natural do solo.

A curva apresenta características de formação de multicamadas de adsorção do metal, pois se pode perceber a formação de mais de um patamar de saturação. Considerando, portanto, somente o primeiro patamar, o qual corresponde à monocamada, 
que finaliza em cerca Ce igual a $72 \mathrm{mg} \mathrm{L}^{-1}$, procedeu-se à análise do modelo de isoterma que melhor representa esse processo.

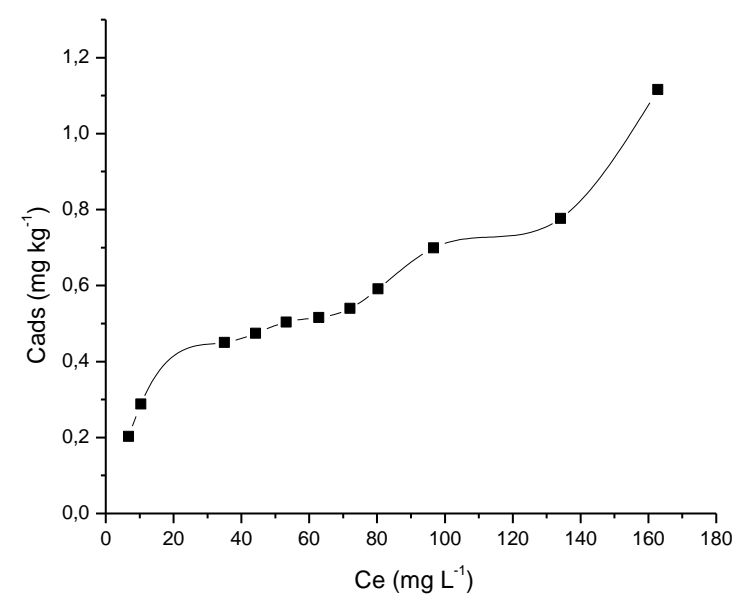

Figura 2. Isoterma de adsorção de $\mathrm{Cd}^{+2}$ no solo amostrado em pH natural do solo Fonte: Autores, 2012

A linearização da equação de Langmuir resultou em reta com $R^{2}=0,99925$ enquanto a de Freundlich com $R^{2}=0,98562$. Assim, o modelo de Langmuir é o que melhor se ajusta aos dados de adsorção do $\mathrm{Cd}$ ao solo. A capacidade máxima de adsorção da monocamada, $Q_{M}$, apresentou valor de $0,64 \mathrm{mg} \mathrm{kg}^{-1}$, o valor de $\mathrm{K}_{\mathrm{L}}$ foi calculado em 0,072 $\mathrm{L} \mathrm{kg}^{-1}$, o que indica a fraca energia de ligação entre o solo e o metal, ou seja, adsorção física. Apesar da menor correlação linear da isoterma de Freundlich, a mesma foi utilizada para estimar os valores de $\mathrm{K}_{f}$ e $\mathrm{n}$. $\mathrm{O}$ valor de $\mathrm{K}_{\mathrm{f}}$ resultou igual a 0,105, implicando que o solo retém pouco o metal, a adsorção é pequena. Por sua vez, o valor de $n=2,56$ indica que a isoterma tem o comportamento do tipo $L$, segundo Falone (2004), ou seja, há uma diminuição da disponibilidade dos sítios de adsorção quando a concentração do adsorvato aumenta, por sua vez, a interação adsorbato-adsorbato permite a formação de multicamadas, isotermas do tipo L3, conforme verificado na Figura 2, essas formas mais complexas de isotermas estão relacionadas com a não uniformidade nos tamanhos dos poros do material adsorvente (FUNGARO et al., 2009).

\subsubsection{Isoterma de adsorção com variação do pH}


Fixou-se a concentração inicial de metal em $70 \mathrm{mg} \mathrm{L}^{-1}$ e variou-se $\mathrm{opH}$ do meio com adições de solução de $\mathrm{HCl}$ ou de $\mathrm{NaOH} 0,1 \mathrm{~mol} \mathrm{~L}^{-1}$ obtendo-se assim, valores de $\mathrm{pH}$ entre 2,0 e 8,0. Seguindo-se o procedimento conforme descrito no item 3.5.2, foram obtidos os valores das concentrações finais de Cádmio (Ce). Os dados obtidos foram graficados em função de $\mathrm{Ce}$, obtendo-se a Figura 3 abaixo.

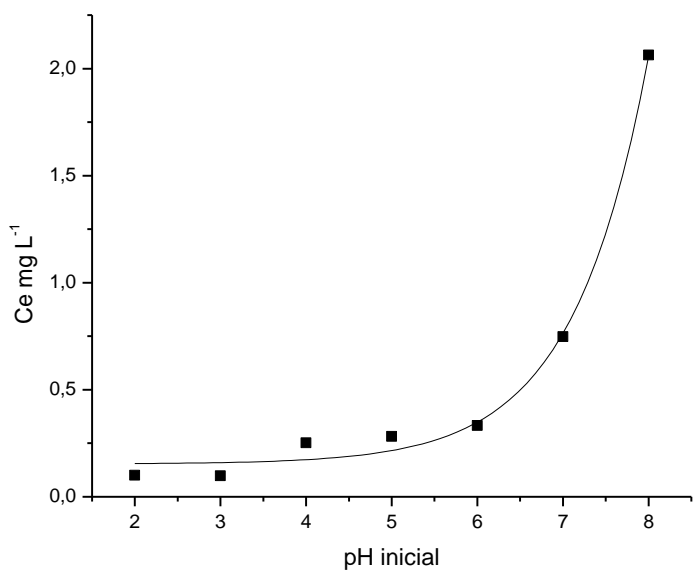

Figura 3. Gráfico de concentração do metal no equilíbrio versus pH inicial do meio Fonte: Autores, 2012

Observa-se uma correlação exponencial crescente entre a adsorção e $\circ \mathrm{pH}$ do meio. Acima de $\mathrm{pH}=9,0$ observou-se a formação de precipitado, fato que pode ser explicado devido a formação de espécies complexas insolúveis, segundo Pierangeli et al. (2005), as formas mais comuns seriam do tipo $\mathrm{Cd}(\mathrm{OH})^{+}$e $\mathrm{Cd}(\mathrm{OH})_{2}$, que ocorrem a partir de $\mathrm{pH} \geq 6,5$ até $\mathrm{pH}=10,1$, que corresponde ao $\mathrm{pK}_{1}$ de hidrólise do $\mathrm{Cd}$. Nas condições experimentais deste estudo, apenas o íon livre $\mathrm{Cd}^{+2}$ está disponível para as interações de superfície. O aumento na capacidade de adsorção, com o aumento do $\mathrm{pH}$, pode ser então, atribuído à desprotonação das superfícies de troca e à consequente geração de cargas negativas, as quais ocorrem em valores de $\mathrm{pH}$ mais elevados, assim, a correlação positiva foi confirmada. Com a diminuição do $\mathrm{pH}$, a adsorção de $\mathrm{Cd}^{2+}$ diminui tal fato pode ser explicado pela competição dos íons $\mathrm{H}^{+}$, pelos sítios de adsorção, visto que, segundo McBride (1989), os íons $\mathrm{H}^{+}$podem deslocar frações do metal adsorvido. 


\subsubsection{Isotermas de adsorção em função da variação da força iônica do meio}

Para a obtenção das isotermas, os experimentos seguiram o procedimento conforme descrito no item 3.5.3. Com os dados tratados, conforme citado anteriormente, foi obtida a isoterma em força iônica igual a $0,03 \mathrm{~mol} \mathrm{~L}^{-1}$, cujo comportamento segundo Barros (2004), pode ser classificada como de Langmuir e favorável. Foi possível verificar que a equação de Langmuir melhor se adequou aos dados experimentais, corroborando o fato da isoterma ter sido classificada como do tipo Langmuir.

Para obtenção das isotermas na força iônica de $0,30 \mathrm{~mol} \mathrm{~L}^{-1}$, seguiu-se o mesmo procedimento. A isoterma obtida é classificada como linear, para as quais a quantidade adsorvida é proporcional à concentração do soluto, diferentemente das favoráveis, nas quais grandes quantidades adsorvidas são obtidas em baixas concentrações de adsorbato. Como esperado o melhor ajuste dos dados ocorreu para o modelo de Langmuir, pois é possível que esta linearidade corresponda ao primeiro trecho do tipo de isoterma segundo Langmuir.

A isoterma obtida em meio de $\mathrm{I}=3,00 \mathrm{~mol} \mathrm{~L}^{-1}$ apresenta tendência de linearidade em baixas concentrações, Ce até cerca $30 \mathrm{mg} \mathrm{L}^{-1} \mathrm{e}$, a partir de Ce maior que $50 \mathrm{mg} \mathrm{L}^{-1} \mathrm{a}$ quantidade adsorvida começa a diminuir, este comportamento é típico de isotermas do tipo desfavorável, quando altas concentrações de soluto são necessárias obtendo-se baixa adsorção. Visto que esta apresenta características de comportamento desfavorável, nenhum dos dois modelos matemáticos ajustou-se adequadamente aos dados, ainda assim, foram calculados os parâmetros das isotermas.

A isoterma em I $=0,1 \mathrm{~mol} \mathrm{~L}^{-1}$ possui características do tipo de isoterma de Langmuir e ocorre de maneira favorável à adsorção. A partir dos modelos matemáticos, pode-se observar o melhor comportamento do modelo de Langmuir. $\mathrm{A}$ isoterma em I = $1,00 \mathrm{~mol} \mathrm{~L}^{-1}$, apresentou comportamento similar à isoterma obtida em força iônica igual a $3,00 \mathrm{~mol} \mathrm{~L}^{-1}$, apresenta linearidade em baixas concentrações, e a partir de $\mathrm{Ce}=80 \mathrm{mg} \mathrm{L}^{-1}$ a quantidade adsorvida decresce, característico de isotermas do tipo desfavorável, mesmo assim, foram calculados os valores das constantes referentes às isotermas. A 
Tabela 2 resume os parâmetros obtidos das isotermas de Langmuir e Freundlich nas diferentes condições de força iônica.

Tabela 2. Parâmetros obtidos das isotermas de Langmuir e Freundlich nas diferentes forças iônicas

\begin{tabular}{cccccc}
\hline $\begin{array}{c}\text { Parâmetros } \\
\text { das isotermas }\end{array}$ & $\begin{array}{c}\mathbf{I}=\mathbf{0 , 0 3} \\
\mathbf{m o l ~ L}^{-1}\end{array}$ & $\begin{array}{c}\mathbf{I = 0 , 1 0} \\
\mathbf{M o l ~ L}\end{array}$ & $\begin{array}{c}\mathbf{I}=\mathbf{0 , 3 0} \\
\mathbf{m o l ~ L}^{-1}\end{array}$ & $\begin{array}{c}\mathbf{I = 1 , 0 0} \\
\mathbf{M o l ~ L}^{-1}\end{array}$ & $\begin{array}{c}\mathbf{I = 3 , 0 0} \\
\mathbf{m o l ~ L}^{-1}\end{array}$ \\
\hline $\mathbf{K}_{\mathbf{L}}\left(\mathbf{L ~ k g}^{-1}\right)$ & 0,06 & 0,06 & 0,12 & 1,38 & 0,22 \\
$\mathbf{Q}_{\mathbf{M}}\left(\mathbf{m g ~ k g}^{-1}\right)$ & 1,54 & 0,42 & 3,13 & 0,45 & 1,15 \\
$\mathbf{K}_{\mathbf{f}}$ & 0,13 & 0,08 & 1,4 & 0,34 & $1,23.10^{-3}$ \\
$\mathbf{n}$ & 1,56 & 2,70 & 6,25 & 14,29 & 0,57 \\
\hline
\end{tabular}

Fonte: Autores, 2013

Da comparação dos processos de adsorção, os três primeiros, em força iônica iguais a 0,$03 ; 0,10$ e $0,30 \mathrm{~mol} \mathrm{~L}^{-1}$ foram aqueles que melhor se ajustaram ao comportamento típico de isoterma de Langmuir, sendo assim, a comparação dos parâmetros dispostos na Tabela 2 acima, permite inferir que todas apresentam baixa afinidade, pois $K_{L}$ menor do que 1. A isoterma na força iônica $0,30 \mathrm{~mol} \mathrm{~L}^{-1}$ foi a que apresentou maior $\mathrm{Q}_{\mathrm{M}}$. Com relação aos parâmetros de Freundlich, também a isoterma em força iônica $0,30 \mathrm{~mol} \mathrm{~L}^{-1}$ apresenta maior capacidade de adsorção, ou seja, maior valor de $\mathrm{K}_{\mathrm{f}}$, e maior afinidade solo-soluto, verificado pelo valor de $\mathrm{n}$.

Portanto, percebe-se que a isoterma em I $=0,30 \mathrm{~mol} \mathrm{~L}^{-1}$ foi a que apresentou os maiores valores dos parâmetros, os quais são coerentes entre si, ou seja, maior $n$ e maior $\mathrm{K}_{\mathrm{L}}$, visto que ambos relacionam-se com afinidade solo-soluto, e maiores valores de $Q_{M} e$ $\mathrm{K}_{\mathrm{f}}$, relacionados com quantidade e capacidade de adsorção, respectivamente.

Para verificar a correlação da força iônica na capacidade de adsorção dos íons $\mathrm{Cd}^{+2}$ no solo, utilizou-se a concentração de equilíbrio de $30 \mathrm{mg} \mathrm{L}^{-1}$ do metal e assim traçou-se o gráfico de Cads em função da força iônica, como é apresentado na Figura 4 abaixo: 


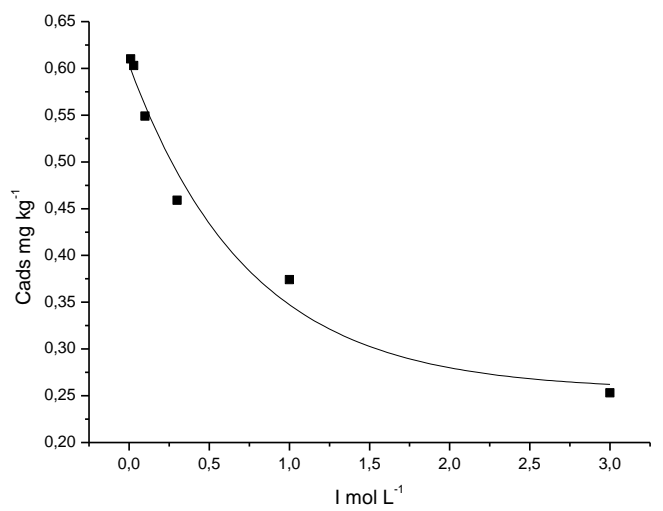

Figura 4. Gráfico de concentração de metal adsorvido versus força iônica para adsorção de Cádmio ao solo Fonte: Autores, 2012

Os dados mostram correlação negativa entre a adsorção e o aumento da força iônica. Isso devido aos íons $\mathrm{Ca}^{+2}$ serem fortes competidores frente aos íons $\mathrm{Cd}^{+2}$ pelos sítios de adsorção do solo em função das similaridades do tamanho de seus raios iônicos, do aumento da atividade dos íons livres e às mudanças do potencial eletrostático no plano de adsorção (BARROW, 1986 e SPARKS, 2003).

\subsection{Relação da energia livre $\left(\Delta \mathbf{G}^{\circ}\right)$ com a capacidade de adsorção do metal no solo}

As mudanças na energia livre que ocorrem quando um elemento é adsorvido podem ser úteis para medição da extensão ou da força que determinada reação ocorre. Seu sinal indica se a reação é espontânea ou não espontânea, à temperatura e pressão constantes. Quanto maior a magnitude da energia livre, maior a força de reação do soluto pela superfície adsorvente (IGLESIAS et al., 2007). A energia livre pode ser calculada, seguindo a equação termodinâmica (3):

$$
\Delta \mathrm{G}^{\circ}=\mathrm{RT}[\ln \mathrm{Ce}-\ln \mathrm{Ci}]
$$

Em que $\Delta \mathrm{G}^{\circ}$ tem unidades de $\mathrm{J} \mathrm{mol}^{-1}, \mathrm{R}$ é a constante universal dos gases, cujo valor é $8,314 \mathrm{~J} \mathrm{~mol}^{-1} \mathrm{~K}^{-1}$, e T indica a temperatura, no presente trabalho foi de $298,15 \mathrm{~K}$. 
Os valores calculados de energia livre para todas as forças iônicas estudadas, foram negativos, o que demonstra que a reação de adsorção de $\mathrm{Cd}^{+2}$ foi termodinamicamente espontânea. Os dados estão apresentados na Tabela 3.

Tabela 3. Valores de $\Delta \mathrm{G}^{\circ}$ de adsorção de $\mathrm{Cd}$ ao solo amostrado em cada uma das forças iônicas avaliadas

\begin{tabular}{|c|c|c|c|c|c|}
\hline $\mathrm{I} / \mathrm{mol} \mathrm{L}^{-1}$ & 0,03 & 0,10 & 0,30 & 1,00 & 3,00 \\
\hline$\Delta \mathrm{G}^{\circ} / \mathrm{J} \mathrm{mol}^{-1}$ & $-2,45$ & $-0,57$ & $-0,44$ & $-0,37$ & $-0,30$ \\
\hline
\end{tabular}

Fonte: Autores, 2012

Pode-se observar que os valores de $\Delta$ Go de adsorção diminuíram conforme o aumento da força iônica, indicando dessa forma, a diminuição da espontaneidade da adsorção do metal no solo, isso devido à competição entre os $\mathrm{Cd}^{+2}$ e os íons $\mathrm{Ca}^{+2} \mathrm{e} \mathrm{Na}^{+}$, oriundos das soluções utilizadas para obtenção da força iônica desejada.

\section{CONCLUSÃO}

Considerando que o solo analisado é essencialmente arenoso, de acidez média e CTC relativamente alta, é possível que tais fatores tenham contribuído para o fato da adsorção ser classificada como pequena. Tendo em vista o baixo teor de M.O. do solo esta pode dificultar a percolação de água e aumentar o escoamento superficial, e considerando também a baixa capacidade de adsorção do solo, é possível que o íon metálico seja carreado superficialmente para corpos d'água em eventos de chuva.

$O$ processo de adsorção adequou-se melhor ao modelo de Langmuir. $O$ efeito do pH mostrou correlação positiva entre a capacidade de adsorção e o aumento deste, já o aumento da força iônica do meio mostrou correlação negativa com a capacidade de adsorção. O meio com força iônica $0,30 \mathrm{~mol} \mathrm{~L}^{-1}$ foi o que apresentou maiores valores dos parâmetros dos modelos de Langmuir e Freundlich.

O processo de adsorção foi termodinamicamente espontâneo, conforme os valores obtidos para $\Delta G^{0}$, nas diferentes condições de força iônica, com o aumento desta, a espontaneidade diminuiu e a força de interação íon-superfície também diminui. 
Caso este solo venha ser utilizado para prática agrícola e receber periodicamente cuidados agrícolas, haverá a necessidade do monitoramento de metais pesados, pois tais íons metálicos podem ser adicionados ao solo por meio da fertilização. O presente estudo foi importante para estabelecer os parâmetros da adsorção do Cádmio ao solo e concluir que este íon metálico quando em quantidades superiores à capacidade adsortiva do solo, está sujeito à lixiviação para cursos d'água ou à biodisponibilização às plantas.

\section{REFERÊNCIAS}

BARROS, M. A. S. D.; ARROYO, P, A. CAPÍTULO V: Métodos de remoção de cromo de águas residuais- Métodos de adsorção. Departamento de Engenharia Química, Maringá, v.2, 2004.

BARROW, N. J. Testing a mechanistic model. IV. Describing the effect of pH on Zn retention by soils. J. of Soil Science, v.37, 1986.

BOHN, H .L.; McNEAL, B. L.; O'CONNOR, G. A. Soil chemistry. Canada: John Wiley \& Sons. 3. ed., 2001. 307p.

FALONE, S. Z.; BIEIRA, E. M. Adsorção/Dessorção do explosivo tetril em turfa e em argissolo vermelho amarelo. Quim. Nova, v.27, n.6, p.849-854, 2004.

FERNANDES, R. B. A.; LUZ, W. V.; FONTES, M. P. F. e FONTES, L. E. F. Avaliação da concentração de metais pesados em áreas olerícolas no Estado de Minas Gerais. Rev. Bras. Eng. Agríc. Ambient. [online]. v.11, n.1, pp. 81-93, 2007.

FUNGARO, D. A.; IZIDORO, J. C.; BRUNO, M. Aplicação de material zeolítico sintetizado de cinzas de carvão como adsorvente de poluentes em água. Ecl. Quim., v.34, n.1, p.45-50, 2009.

GONÇALVES, L. M. Análises Químicas e Determinação de Metais em Fertilizantes e Solo de Cultivo de Laranja. Monografia UNESP - IBILCE, 2009. 
IGLESIAS, C.; CASAGRANDE, J. C.; ALLEONI, L. R. F. Efeito da natureza do eletrólito e da força iônica na energia livre da reação de adsorção de níquel em solos. Rev. Bras. Ciênc. Solo [online]. v.31, n.5, p.897-903, 2007.

LAIR, G. J.; GERZABEK, M. H.; HABERHAUER, G.; JAKUSCH, M.; KIRCHMANN H. Response of the sorption behavior of $\mathrm{Cu}, \mathrm{Cd}$ and $\mathrm{Zn}$ to different soil management. J. Plant Nutr. Soil Sci., v.169, p.60-68, 2006.

LEPSCH, I. F. Formação e Conservação dos Solos. São Paulo: Oficina de Textos. 2. ed, 2002.

MA, Q. Y.; LINDSAY, W. L. Estimation of $\mathrm{Cd}^{2+}$ and $\mathrm{Ni}^{2+}$ activities in soils by chelation. Geoderma, v.68, p.123-133, 1995.

MACEDO, R. S. Caracterização Física e Química de solo de Plantação de Laranja da Região de São José do Rio Preto e Estudo da Adsorção de Cádmio no Horizonte Superficial. Monografia UNESP - IBILCE, 2009.

McBRIDE, M. B. Surface chemistry of soil minerals. In Dixon, J. B. \& Weed, S. B. (Eds). Minerals in soil environments. SSSA Book Serie, Soil Society of American, Madison, 1989.

OLIVEIRA, T. S.; COSTA, L. M. Metais pesados em solos de uma topolitosseqüência do Triângulo Mineiro. Rev. Bras. Ciênc. Solo [online]. v.28, n.4, p.785-796, 2004.

PRADO, H. A pedologia simplificada. ARQUIVO DO AGRÔNOMO. n 1. 2. ed. 1995.

PIERANGELI, M. A. P. et al. Efeito do pH na adsorção e dessorção de cádmio em Latossolos brasileiros. Rev. Bras. Ciênc. Solo [online]. v.29, n.4, p.523-532, 2005.

RAIJ, B. van; ANDRADE, J. C.; CANTARELLA, H.; QUAGGIO, J. A. Análise química para avaliação da fertilidade de solos tropicais. Campinas: Instituto Agronômico, 2001. 285p.

SOARES, M. R. Coeficiente de distribuição de metais pesados e sua relação com atributos físico-químicos de solos do estado de São Paulo. Tese (Doutorado em Agronomia) - Escola Superior de Agricultura Luiz de Queiroz. p.202, Piracicaba, 2004. 
SPARKS, D. L. Environmental Soil Chemistry. San Diego Academic Press, 2003. 352p.

SPOSITO, G. The Chemistry of Soils. New York: Oxford University Press, 1989. 277p.

TEMMINGHOFF, E. J. M.; ZEE, S. E. A. T. M. van der; HANN, F. A. M. Speciation and calcium competition effects on cadmium sorption by sandy soil at various $\mathrm{pHs}$. European Journal of Soil. Science, Oxford, v.46, 1995.

TOMÉ JÚNIOR, J. B. Manual para interpretação de análise de solo. Guaíba: Agropecuária, 1997. 247p. 